\title{
Thermal stability of PMMA-clay hybrids
}

\author{
TANUSHREE CHOUDHURY* and NIRENDRA M MISRA \\ Department of Applied Chemistry, Indian School of Mines University, Dhanbad 826 004, India
}

MS received 9 December 2008

\begin{abstract}
Materials with small particle size are being extensively used in composites and hybrid materials. Exfoliated clay-polymer hybrids show enhanced properties. Exfoliation of clay platelets can be affected by selecting dispersing agents. In the present work, clay dispersed by natural dispersant (soap stone powder), cetyl trimethyl ammonium bromide (CTAB) dispersed clay and acid clay (amorphous clay) are taken. They are then polymerized with poly methyl methacrylate (PMMA) by solution intercalation method. The thermal stability of these different clay-PMMA hybrids have been studied and compared with that of pure PMMA by differential scanning calorimeter (DSC). The bonding of clay with PMMA has been studied by IR. Morphology of clay-PMMA hybrids has been shown by SEM and XRD which indicate partially exfoliated structure in T606-4 and intercalated structures in T606-6 and T606-2.
\end{abstract}

Keywords. Dispersants; DSC; exfoliation; hybrid; nanoclay; poly (methyl methacrylate); SEM; thermal stability; XRD.

\section{Introduction}

Clay minerals are hydrated alumino-silicates having layered structure. Clay particles that have the sizes of a few nanometers thick, if properly dispersed in the polymer matrix impart unique combination of physical and chemical properties that make these composites suitable for making coatings and films for a variety of industrial applications. Clay minerals are composed of one central octahedral layer sandwiched between two tetrahedral layers. Isomorphous substitution of tetravalent Si by trivalent $\mathrm{Al}$ in tetrahedral layer and trivalent $\mathrm{Al}$ by divalent $\mathrm{Mg}$ in octahedral layer leads to charge deficiency which is compensated by compensating cations on the layer surfaces. These cations then get easily exchanged by other cations in solution. Thus clay minerals bear potential of forming organic-inorganic hybrid materials.

There are three types of polymer-clay hybrids as reported in literature (Ruiz-Hitzky 2004). They are (i) intercalated hybrids which result from the intracrystalline insertion of organic compounds inside the layers of certain lamellar solids, (ii) exfoliated or delaminated hybrids which are formed when the layers of clay are delaminated and the resulting platelets are homogenously dispersed throughout the polymer matrix and (iii) sol-gel hybrids which refer to organically modified silicates or ceramics.

Exfoliated polymer clay hybrids exhibit improved modulus, lower thermal expansion coefficient, gas permeability, higher swelling resistance and enhanced ionic

*Author for correspondence (tanu_c79@yahoo.co.in) conductivity compared with pristine polymers due to nanoscale structure of hybrids and synergism between polymer and silicate (Xu et al 2003). Delamination (or exfoliation) of clay depends on the dispersion of clay, and properties of the hybrids depend on the interaction of delaminated clay with the polymer or fibre. In order to obtain enhancement in these properties, surface of the clay which is hydrophobic in nature needs to be modified so that it can interact with hydrophobic polymers. Surface of the clay is generally modified by cation exchange process. The ability of clays to exchange cations between each of their individual layer and retain them is a unique characteristic. The intercalated cations can be exchanged by other cations by treatment of other cations in solution. Thus cation exchange capacity can be defined as the maximum amount of cations that a given amount of clay can take up and is constant (Van Olphen 1963). The clay platelets are held together by strong electrostatic forces of attraction between its layers and inter-gallery cations (Ma et al 2003). As a result of modification of its surface by cation-exchange process, the layers get separated or delaminated due to reduction in surface energy. Alkyl ammonium cations incorporated in organosilicates lower the surface energy of inorganic host and improve the wetting characteristics with polymer (Sinha Ray and Okamato 2006). It provides functional group that can react with polymer or initiate polymerization of monomers to improve interfacial strength between inorganic host and polymer (Sinha Ray and Okamato 2006).

The polymer clay hybrids are obtained by the following three main methods: (i) in situ polymerization, (ii) exfoliation-adsorption and (iii) melt intercalation (Ale- 
xandre and Dubois 2000). Among thermoplastic-clay hybrids, PMMA has been widely used as a model matrix because it can be easily polymerized in bulk (in situ) solution, suspension and emulsion techniques ( $\mathrm{Xu}$ et al 2006). Numerous works have been reported in literature on PMMA as PMMA-clay hybrids have a potential advantage in reducing flammability, gas permeability and improving thermal and mechanical properties without any loss in optical clarity (Zheng et al 2005).

In the present work, we examine hybrids of poly (methyl methacrylate) (PMMA) with three different types of clay (clay dispersed by natural dispersant, CTAB treated clay and acid or amorphous clay). Hybrid formation is evaluated by scanning electron microscope (SEM). Bonding between clay and PMMA is being shown by FTIR. The thermal stabilities of the resulting hybrids have been compared by DSC. The present study was stimulated by the observation of earlier works where it is shown that surfactant treated clay has a major role on the thermal stability of PMMA as compared to pristine clay.

\section{Experimental}

\subsection{Materials}

Clay used in this experiment was mainly Bikaner bentonite. Cetyl trimethyl ammonium bromide (CTAB) used for dispersing clay was acquired from Ranbaxy Fine Chemicals Ltd. Polymer PMMA used for intercalation was of molecular weight 15,000 and bought from Acros Organics. Natural dispersant or soap stone powder was acquired from natural source.

\subsection{Modification of clay}

Clay was made organophilic by $\mathrm{CTAB}$ and a natural surfactant. To $1 \mathrm{~g}$ clay, $0.1 \%$ dispersant solution $(0.01 \mathrm{~g}$ of dispersant in $10 \mathrm{ml}$ water) was mixed under constant stirring for $4 \mathrm{~h}$ so that clay gets well dispersed in it. One drop of clove oil was added to the naturally dispersed clay suspension to keep it bacteria free. The resulting suspension was centrifuged and dried in room temperature.

\subsection{Preparation of acid/amorphous clay}

Known amount of clay was taken and kept in furnace till the temperature reached $600^{\circ} \mathrm{C}$ and it was immediately taken out and quenched in $0 \cdot 1 \mathrm{~N} \mathrm{HCl}$ solution. The resulting solution was centrifuged and dried at room temperature.

\subsection{Synthesis of PMMA/clay hybrids}

PMMA-clay hybrid was prepared by solution-intercalation method (Kim et al 2005). $10 \mathrm{wt} \%$ clay was used to prepare the hybrid. $1 \mathrm{~g}$ PMMA was dissolved in acetone and stirred vigorously in a round bottomed flask fitted with stopper at $40^{\circ} \mathrm{C}$ for $30 \mathrm{~min}$. The organophilic clay (10 wt\%) was added to the polymer solution and continued to stir for $1 \mathrm{~h}$. The solution product was then filtered off and washed thoroughly. The product was then dried at room temperature.

\subsection{Instrumentation}

DSC of PMMA-clay hybrid was performed on differential scanning calorimeter Perkin Elmer DSC-7 under nitrogen atmosphere at a scan rate of $20^{\circ} \mathrm{C} / \mathrm{min}$. IR was done on Perkin Elmer FTIR Spectrometer Spectrum 2000. SEM of PMMA-hybrids was taken using Hitachi S-3400N, Japan, using $3 \mathrm{kV}$. XRD of PMMA-clay hybrids was done using X'Pert Software, Phillips, powder diffractometer equipped with $\mathrm{Cu}-\mathrm{K} \alpha$ generator $(\lambda=1.5405600)$. Generator tension was $35 \mathrm{kV}$.

\section{Results and discussion}

\subsection{DSC analysis}

DSC showed a $9 \cdot 12^{\circ} \mathrm{C}$ (as indicated in table 1a) increase in the glass transition temperature $\left(T_{\mathrm{g}}\right)$ of the hybrid prepared with clay (dispersed by natural dispersant-T606-4) as compared to pure PMMA (T703-10). This result was higher than hybrid prepared with acid clay (T606-2) which showed an increase in $T_{\mathrm{g}}$ of $7.47^{\circ} \mathrm{C}$ while $\mathrm{CTAB}$ dispersed clay-PMMA hybrid (T606-6) showed an increase of $6.45^{\circ} \mathrm{C}$. Thus clay dispersed by natural dispersant (T606-4) provides greater thermal stability to PMMA as compared to the other two clays.

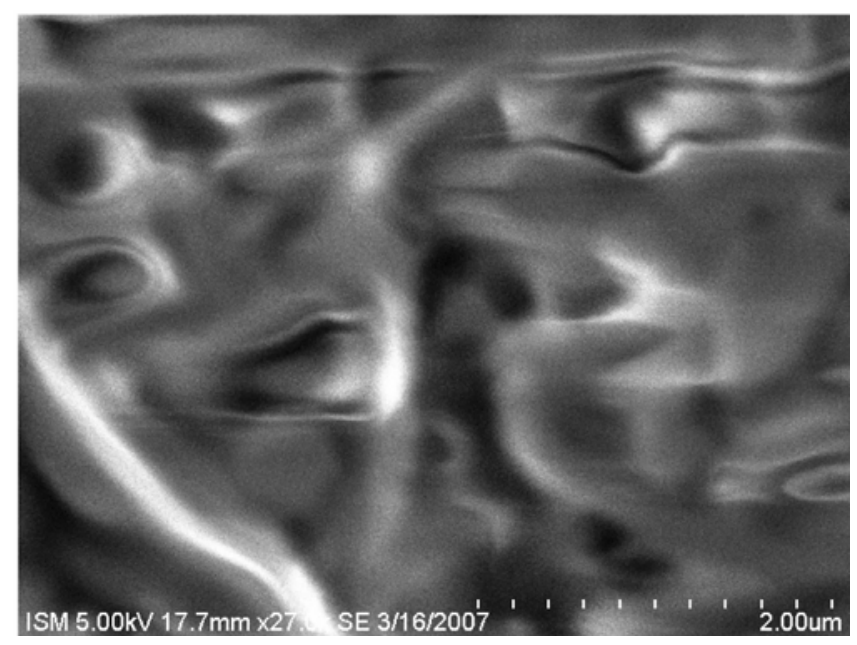

Figure 1. SEM of PMMA-clay hybrid dispersed by natural dispersant showing partially exfoliated structure. 


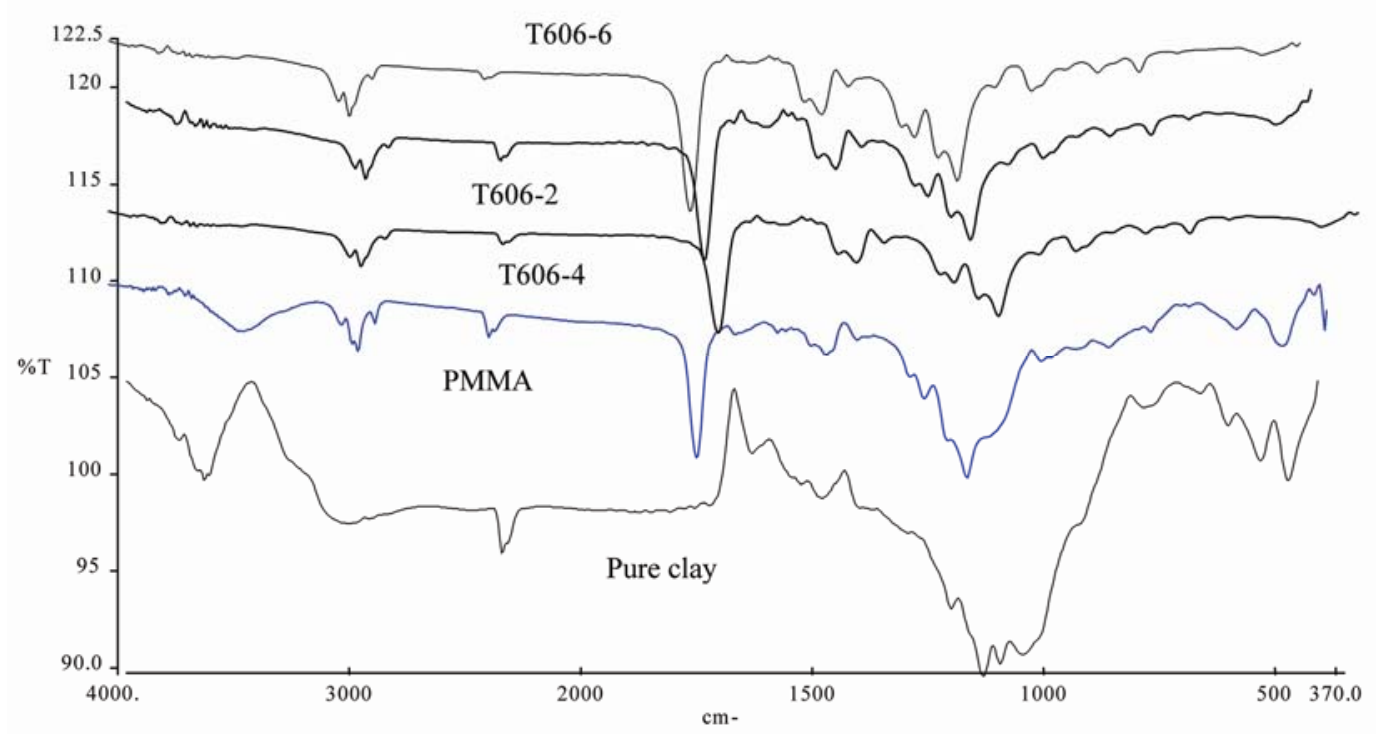

Figure 2. FTIR spectra of PMMA-clay hybrids.

Table 1a. Table showing $T_{\mathrm{g}}$ of PMMA-clay hybrids.

\begin{tabular}{|c|c|c|c|}
\hline S1. no. & Type of hybrid & Structure & $T_{\mathrm{g}}\left({ }^{\circ} \mathrm{C}\right)(\mathrm{DSC})$ \\
\hline 1. & Pure PMMA & - & $97 \cdot 12$ \\
\hline 2. & $\begin{array}{l}\text { PMMA + clay } \\
\text { (dispersed by natural } \\
\text { dispersant) }\end{array}$ & $\begin{array}{l}\text { Partially } \\
\text { exfoliated }\end{array}$ & $106 \cdot 24$ \\
\hline 3. & PMMA + acid clay & Intercalated & 104.59 \\
\hline 4. & PMMA + CTAB clay & Intercalated & $103 \cdot 57$ \\
\hline
\end{tabular}

Table 1b. Table showing $d$-spacing of various organically modified PMMA-clay hybrids

\begin{tabular}{lccc}
\hline S1. no. & Sample name & $d$-spacing $(\mathrm{nm})$ & Angle $(2 \theta)$ \\
\hline 1. & T606-4 & 3.56 & 2.47 \\
2. & T606-2 & 2.85 & 3.09 \\
3. & T606-6 & 2.74 & 3.21 \\
4. & Pure MMT & 1.6 & 5.44 \\
\hline
\end{tabular}

\subsection{SEM analysis}

Figure 1 shows SEM micrograph of PMMA-clay hybrid where clay has been dispersed by natural dispersant (T606-4). It is a partially exfoliated structure showing individual clay layers (not in registry) with PMMA embedded in the galleries of clay. PMMA-clay hybrids of acid clay (T606-2) and CTAB treated clay (T606-6) show intercalated structures as can be seen from $d$-spacing data supported by XRD. Clay dispersed by natural dispersant might have helped in increasing the interlayer spacing of clay thus fastening intercalation of PMMA within the galleries of clay leading to partially exfoliated structure.

\subsection{FTIR analysis}

IR spectra of all PMMA-clay hybrids give a distinct absorption peak at $1730 \mathrm{~cm}^{-1}(\mathrm{C}=\mathrm{O}$ stretching $), 2996 \mathrm{~cm}^{-1}$ and $2952 \mathrm{~cm}^{-1}\left(-\mathrm{CH}_{2}\right.$ stretching), wide absorption peak at $3400-3600 \mathrm{~cm}^{-1}$ (H-bond). Characteristic montmorillonite peak was observed between 900 and $1000 \mathrm{~cm}^{-1}$ (Si-O-Si stretch) which was very much reduced in the spectrum recorded for the hybrids as can be seen in figure 2. This may be due to the fact that PMMA being grafted on the clay surface.

\subsection{XRD analysis}

The $d$-spacing observed for virgin MMT is $1.6 \mathrm{~nm}$ $(2 \theta=5.44 \AA)$ which always increases upon organic modification (Jash and Wilkie 2005; Stadtmueller et al 2005). The $d$-spacings for the various organically modified clays are shown in table $1 \mathrm{~b}$. It is thus clear that $d$-spacing is greatest in T606-4 (PMMA-clay hybrid where clay has been dispersed by natural dispersant), thus indicating that exfoliated structure may have been attained.

\section{Conclusions}

Synthesis of PMMA/clay hybrids by solution intercalation method using three different types of clays (clay dispersed by natural dispersant, CTAB treated clay, acid/amorphous clay) resulting in partially exfoliated and intercalated structures, respectively was described. The different morphologies of the hybrids resulted in significant thermal property improvements in comparison to pristine polymer. Partially exfoliated hybrid of PMMA 
with clay (dispersed by natural dispersant-T606-4) exhibited an increase in $T_{\mathrm{g}} 9 \cdot 12^{\circ} \mathrm{C}$ higher than PMMA while for intercalated structures of PMMA with $\mathrm{CTAB}$ clay (T606-6) and acid clay (T606-2) showed only $6 \cdot 45^{\circ} \mathrm{C}$ and $7.47^{\circ} \mathrm{C}$ increase in $T_{\mathrm{g}}$. Using PMMA/clay hybrids, ion selective membranes can be developed for various metal ion detections. Other applications lie in film packaging and gas storage (Meneghetti and Qutubuddin 2006).

\section{References}

Alexandre M and Dubois P 2000 Mater. Sci. \& Eng. 281 Jash P and Wilkie C A 2005 Polym. Degrad. \& Stab. 88401

Kim H B, Choi J S, Lee C H, Lim S T, Jhon M S and Choi H J 2005 Eur. Polym. J. 41679
Ma J, Xiu J, Ren H J, Yu Z and Mai Y 2003 Polymer 444619 Meneghetti P and Qutubuddin S 2006 Thermochim. Acta 44274 Ruiz-Hitzky E 2004 Organic-inorganic materials: From intercalation chemistry to devices, in Functional hybrid materials (eds) Pedro-Gomez Romero and Clement Sanchez (Weinheim: Wiley VCH) pp 15-49

Sinha Ray S and Okamato M 2003 Prog. Polym. Sci. 281539

Stadtmueller L M, Ratinac K R and Ringer S P 2005 Polymer 469574

Van Olphen H (ed.) 1963 Clay colloid chemistry (London: Wiley Interscience)

Xu W, Liang G, Zhai H, Tang S, Hang G and Pan W 2003 Eur. Polym. J. 391467

Xu Y, Brittain W J, Xue C and Eby R K 2006 Polymer 453735 Zheng X, Jiang D D and Wilkie C A 2005 Thermochim. Acta 435202 